\title{
Immunohistochemical Profile, Pattern of Recurrence, and Time to Progression of Non-Metastatic Breast Cancer Patients of the Department of Health-Breast Cancer Medicines Access Program
}

\author{
Nelson A. Laja, ${ }^{1}$ Arthur Gregory A. Lui, ${ }^{1}$ Joar Kent P. Gumapon, ${ }^{2}$ Corazon A. Ngelangel, $, 1,3,4$ \\ Anna Melissa S. Guerrero, ${ }^{3}$ Dennis L. Sacdalan, ${ }^{1}$ Rachel Marie B. Rosario ${ }^{4}$ and Romeo V. Marcaida ${ }^{4}$ \\ ${ }^{1}$ Section of Medical Oncology, Department of Medicine, College of Medicine and Philippine General Hospital, University of the Philippines Manila \\ ${ }^{2}$ Section of Medical Oncology, Department of Health-Jose R Reyes Memorial Medical Center \\ ${ }^{3}$ Department of Health-National Center for Pharmaceutical Access Management \\ ${ }^{4}$ Philippine Cancer Society
}

\begin{abstract}
Background. Breast cancer remains to be the leading cause of malignancy among women and survival rates vary worldwide. Molecular and immunohistochemical (IHC) profiling of breast cancer has emerged to improve treatment, which led to 6 different breast cancer subtypes luminal-A, luminal-B, Her-2 enriched, basal-like, claudin low, and normal breast. Essentially, this guides clinicians as to the choice of treatment and prognostication of disease. This study evaluates the characteristics of the different IHC subtypes of breast cancer among Filipinos as to pattern of recurrence and time to progression (TTP) within their $1^{\text {st }} 2$ years of follow-up.
\end{abstract}

Methods. This is a retrospective cohort study, approved by the University of the Philippines Manila Research Ethics Board (UPMREB). Study population included breast cancer patients enrolled in the DOH-BCMAP and managed at the medical oncology clinics of the Philippine General Hospital (PGH) and Jose R. Reyes Memorial Medical Center (JRRMMC) from 1 May 2011 to 31 December 2013. Patients' demographics, disease and treatment profile were gathered from the medical charts. Patients were grouped into 12 different IHC subtypes utilizing only IHC staining results of Her2neu, ER and PR. Disease progression/ relapse and time to progression (TTP) were primary outcomes analyzed and compared between subtypes using SPSS.

Results. There were 368 eligible patients; $50 \%$ were $>50$ years old, $48 \%$ postmenopausal, $34 \%$ stage IIA, and $94 \%$ had invasive ductal carcinoma. About $88 \%$ completed their chemotherapy regimen, mostly AC-T. At 1 to 2 years follow-up, 18\% had disease

Presented and won 3rd place at the Philippine Society of Medical Oncology 2014 Annual Convention; presented and won 1st place at the Philippine Breast Cancer Society 2014 Annual Convention; presented and won Best Poster at the PCP 2015 Annual Convention.

Corresponding author: Dennis L. Sacdalan, MD, MCMMO, PhD (cand) Mol Bio Section of Medical Oncology

Department of Medicine

Philippine General Hospital

University of the Philippines Manila

Taft Avenue, Ermita, Manila 1000 Philippines

Tele/Fax: +632 5263775

Email: dennis.sacdalan@gmail.com progression, mostly distant metastasis, with HER2neu(-)/ ER(-)/PR(-), HER2(+), and HER2neu(-)/ER(+)/PR(+) subtypes having the most number of disease progression. The HER2neu(-)/ER(-)/PR(-) subtype had the shortest median TTP (11 months $\pm 9 \mathrm{sd}$ ). HER2(+) subtype had median TTP of $14 \pm 8 \mathrm{sd}$, while HER2neu(-)/ER(+)/PR(+) had median TTP at $11.6 \pm 7.41 \mathrm{sd}$. The median TTPs among the different IHC subtypes were statistically comparable.

Conclusion. Filipinas with non-metastatic breast cancer after surgery and mainly on adjuvant chemotherapy started to develop disease progression/ relapse within the first 2 years of follow-up; $82 \%$ had no relapse. At these early years of follow-up, the median TTPs among the different breast cancer IHC subtypes who went into relapse were comparable, although HER2neu(+) regardless of ER/PR subtype tended to have more disease progression, followed by HER2neu(-)/ ER(-)/ regardless of PR subtype, and then HER2neu(-)/ER(+)/ regardless of PR subtype. IHC resultant HER2neu(+) regardless of ER/PR and HER2neu(-)/ER(-)/PR(-/+) subtypes can serve as early prognosticators of breast cancer relapse.

Key Words: breast cancer, IHC subtypes, TTP

\section{Introduction}

Breast cancer remains to be the leading cause of malignancy among women worldwide. It is commonly prevalent among the developed world but incidence in developing countries is noticeably increasing. Survival rates vary greatly worldwide, ranging from $60-80 \%$ in the middle to high-income countries and below $40 \%$ in low-income ones. This low survival maybe attributed to the lack of early detection programs, resulting in a high proportion of women presenting with late-stage disease, as well as by the lack of adequate diagnosis and treatment facilities. ${ }^{1}$

Similarly, breast cancer is also the leading cause of malignancy in the Philippines among women (28\%) and even for both sexes combined (15\%). It has the highest registered incidence rate in Asia at 58.9\% among 187 countries over a 30-year period from 1980 to $2010 .{ }^{2}$ Incidence rate starts rising steeply at age 30 with an average annual percentage change of $0.9 \%$. At least 1 of 13 Filipino women 
will develop breast cancer in her lifetime and 3 of 100 women would have a likelihood of getting breast cancer before age 75 . In 2010, breast cancer ranked as the 3rd leading cause of cancer deaths in both sexes (8\%), and the highest among women (18\%). The estimated national agestandardized mortality rate was 11.9 per 100,000 women. One $(1.2 \%)$ of 100 women would have died from breast cancer before age $75 .^{2}$

Several efforts have been made in the past in order to improve management and survival among breast cancer patients; but epidemiological data still showed comparable trend in treatment outcomes and still pose great challenges. Until in the recent time, gene signature studies in breast cancer have paved the way in defining peculiar characteristics of breast cancer through molecular subtyping analysis. Investigations of these subtypes via immunohistochemical (IHC) markers have given insight into the heterogeneous nature of breast cancer, which are biologically discrete and display different behaviors. IHC markers have been found to be predictors for survival, response to systemic therapy, and locoregional or distant recurrences. The analysis of estrogen receptor (ER), progesterone receptor (PR), and Her2neu oncogene expression in breast tissue sub-classifies breast cancer patients, and this is considered standard of care in the approach to breast cancer treatment.

Eroles et $\mathrm{al}^{3}$ classified breast cancer into six different subtypes utilizing ER, PR, HER2, and CK5/6 EGFR IHC and molecular analysis, into luminal-A [ER(+) PR(+) HER2neu(-) CK5/6 EGFR(-)]; luminal-B [(ER(+/-) PR(+/-) HER2neu(-/+) CK5/6 EGFR(-)]; HER2neu-enriched [ER(-) PR(-) HER2neu(+) CK5/6 EGFR(+/-)]; basal-like [ER(-) PR(-) HER2neu(-) CK5/6 EGFR(+)]; claudin-low [ER(-) PR(-) HER2neu(-) CK5/6 EGFR(+/-)], and normal breast [ER(-/+) HER2(-) CK5/6 EGFR(+)]. Basal-like [ER(-) PR(-) HER2neu(-) CK5/6 EGFR(+)] and claudin-low [ER(-) PR(-) HER2neu(-) CK5/6 EGFR(+/-)] are collectively called triple negative breast cancer, considering only negative HER2neu/ER/PR results.

Luminal-A has a better prognosis and is the most common subtype (50-60\%), with a relapse rate of $27.8 \%$ and median survival from the time of relapse of 2.2 years, significantly better than other subtypes with a distinct pattern of recurrence more of bone metastases $(18.7 \%){ }^{4}$ Luminal B (10 to 20\%; with ER(-)/HER2neu(+) combinations) has a more aggressive phenotype, higher histological grade and proliferative index, and worse prognosis than luminal A; survival from time of relapse is lower (1.6 years) with bone $(30 \%)$ as the most common site of distant metastasis; another site is liver (13.8\%). ${ }^{3}$ HER2neu-enriched subtype $(15-20 \%)$ is characteristically poor in prognosis and highly proliferative with high histological grade (75\%), but with the advent of anti-HER2 treatment, survival has substantially improved. ${ }^{3}$ Triple negative breast cancer (10-20\%) of mainly basal-like type, has worse prognosis than luminal subtypes with higher relapse rate in the first 3 years of follow-up. ${ }^{5}$ These triple negative breast tumors have high mitotic index, tumor necrosis, expanding margins and a clear stromal lymphocytic response ${ }^{6}$; the pattern of metastatic relapse is aggressive with predominance for visceral organs, mainly lung, central nervous system and lymph nodes. ${ }^{7}$ Normal breast subtype has $5-10 \%$ occurrence. ${ }^{3}$

Several studies ${ }^{8-17}$ have shown numerous advantages and usefulness of IHC sub-typing in breast cancer in terms of approach in the management of patients and prognostication. However, there are reports showing that the prognostic and etiologic importance of being a heterogeneous disease is complicated by many factors, including the observation that differences in clinical outcomes often correlate with race. Previous studies have shown preliminary evidences and high probabilities of molecular differences across ethnic and geographic groups, and some studies have showed that racial/ethnic differences have been observed among the different molecular subtypes in breast cancer in terms of incidence, prevalence, and treatment outcomes. ${ }^{14,18-21}$ This study describes the characteristic and behavior of the different IHC subtypes among Filipinos with breast cancer, particularly in terms of patterns of- and time to- disease progression within the first 1-2 years follow-up after treatment with surgery and chemotherapy, with hormone therapy and radiotherapy as indicated. How do HER2neu/ ER/ PR IHC sub-types of breast cancer prognosticate the Filipino breast cancer patient, given a Philippine government hospital setting, where resources may only accommodate IHC assays, without the luxury of molecular profiling including gene amplification and CK5/6 EGFR?

\section{Methods}

This is a retrospective cohort study among Filipinos with histologically proven primary breast carcinoma stages I to III-B, who underwent definitive surgery, chemotherapy, and had radiotherapy and hormonal therapy once indicated. They were patients of the medical oncology clinics of the Philippine General Hospital (PGH) and Jose R. Reyes Memorial Medical Center (JRRMMC), two of six satellite institutions of the DOH-Breast Cancer Management Access Program (DOH-BCMAP), which provides fully subsidized medicines for chemotherapy within 15 weeks from definitive surgery, as well as IHC testing for ER, PR, and HER2neu. Philippine Cancer Society provided the patient navigation program for the DOH-BCMAP. This study included those patients enrolled since the program started in JRRMMC (1 May 2011) and PGH (1 January 2012) and followed-up for at least 1 year (31 December 2013 as data-lock).

The University of the Philippines Manila Research Ethics Board (UPMREB) approved the protocol; data confidentiality was observed. 
The database and records of the eligible breast cancer patients were reviewed. Data gathered included birth date, sex, date of enrollment, disease profile, cancer stage, IHC results for HER2-neu (positive, negative, or equivocal), ER (positive or negative), and PR (positive or negative), treatment profile such as type of surgical procedure done (modified radical mastectomy/ MRM or breast conservation surgery/ BCS), chemotherapy regimen and status (complete or incomplete), radiotherapy (if any, given after completion of chemotherapy cycles), and hormonal therapy (if any, given after completion of chemotherapy cycles). Disease progression/ relapse data included progression site (local and distant) and date of recurrences. Recent survival status of patient was gathered (alive, dead, or lost-to-follow-up); for deceased patients, date and cause of death were gathered.

Classification of breast cancer patients into different subtypes was by IHC staining results for HER-2neu, ER, and PR. The IHC tests were all done at Medical Laboratory of the National Kidney and Transplant Institute, East Avenue, Quezon City and interpreted as follows: 1) HER2neu protein over-expression: 0 to +1 as negative, $2+$ as equivocal, and $3+$ as positive (uniform intense membrane staining of $>30 \%$ of invasive tumor cells); 2) ER/PR receptor assay: total score $\leq 2$ as negative, and total score $\geq 3$ as positive. The subjects were classified into different IHC subtypes of breast cancer (Table $1)$.

Table 1. IHC HER2neu/ER/PR subtypes of breast cancer

\begin{tabular}{cccc}
\hline Subtype & HER2neu status & ER status & PR status \\
\hline A & + & + & + \\
B & + & - & + \\
C & - & + & + \\
D & + & + & - \\
E & + & - & - \\
F & - & + & - \\
G & - & - & - \\
H & - & - & + \\
I & E & + & + \\
J & E & + & - \\
K & E & - & + \\
L & E & - & - \\
\hline
\end{tabular}

Legend: (+) positive; (-) negative; (E) equivocal.

Compared to standard subtypes luminal A $[E R(+) P R(+) H E R 2(-)$ CK5/6 EGFR(-)]; luminal B $[(E R(+/-)$ PR(+/-) HER2(-/+) CK5/6 EGFR(-)]; HER2-enriched [ER(-) PR(-) HER2(+) CK5/6 EGFR(+/-)]; basal-like [ER(-) PR(-) HER2(-) CK5/6 EGFR(+)]; claudin-low [ER(-) PR(-) HER2(-) CK5/6 EGFR (+/-)]; and normal breast [ER(-/+) HER2(-) CK5/6 EGFR(+)].

Disease progression (recurrence or distant metastasis) during the 90-day post-surgery period disqualified the patient from study. A disease progression event after 90 days was considered as a study event.

Descriptive statistics was used to describe patient's profile, disease profile, and treatment profile of the study population. Times to progression (local recurrence and/ or distant metastasis) among the different IHC breast cancer subtypes were the primary outcome. Time to progression (TTP), disease-free survival rate (DFS), and overall survival (OS) rate (secondary study outcomes) during the 1-2 years follow-up, from the time of first definitive treatment were evaluated. Risk ratios were computed to compare the time to recurrence/progression (TTP) during the first 1-2 years follow-up; chi-square test was used to determine the significance of the association. Kaplan-Meier survival analyses with log-rank test to assess for significance were done for the DFS and OS rates. Data analysis used SPSS statistical program; a $\mathrm{p}<0.05$ was considered statistically significant.

A limitation of this study is the non-accessibility of FISH, CISH or DISH laboratory tests to verify equivocal IHC HER2neu assays; hence the patient groups with IHC equivocal results were part of the IHC subtypes studied. There were also 42 patients with unspecified IHC results; and 2 patients with incomplete data set. Priority stages to include in the DOH-BCMP were stages IIIA or better, hence stage IIIB is of small proportion.

\section{Results}

There were 368 eligible non-metastatic breast cancer patients enrolled in the DOH-BCMAP from 1 May 2011 to 31 December 2013 in both institutions from JRRMMC and UPPGH (259 and 109, respectively). As shown in Table 2, 49\% were $>50$ years old; $50 \%$ were menopausal; $67 \%$ had no documented family history of cancer; and the average BSA was $1.57 \mathrm{~m}^{2}$.

Table 2. Baseline characteristics

\begin{tabular}{|c|c|c|c|}
\hline \multirow{2}{*}{\multicolumn{2}{|c|}{ Demographic Characteristics }} & \multicolumn{2}{|c|}{ Total $(\mathrm{N}=368)$} \\
\hline & & Frequency & Relative Frequency (\%) \\
\hline \multicolumn{4}{|c|}{ Age Group } \\
\hline & $<35$ year & 25 & $6.79 \%$ \\
\hline$\bullet$ & $35-50$ year & 162 & $44.02 \%$ \\
\hline & $>50$ year & 181 & $49.18 \%$ \\
\hline \multicolumn{4}{|c|}{ Menopausal status } \\
\hline$\bullet$ & Premenopausal & 39 & $10.60 \%$ \\
\hline$\bullet$ & Peri-menopausal & 145 & $39.40 \%$ \\
\hline$\bullet$ & Postmenopausal & 176 & $47.83 \%$ \\
\hline$\bullet$ & Surgical menopause & 8 & $2.17 \%$ \\
\hline \multicolumn{4}{|c|}{ Family History of Cancer } \\
\hline$\bullet$ & None & 179 & 67.04 \\
\hline & Breast & 16 & 5.99 \\
\hline & Ovary & 10 & 3.75 \\
\hline • & Colorectal & 3 & 1.12 \\
\hline & Lung & 2 & 0.75 \\
\hline & Fibrosarcoma & 2 & 0.75 \\
\hline$\bullet$ & Colon & 1 & $0.37 \%$ \\
\hline • & Prostate & 1 & $0.37 \%$ \\
\hline$\bullet$ & Liver & 1 & $0.37 \%$ \\
\hline$\bullet$ & Cancer, NOS & 51 & $19.10 \%$ \\
\hline BSA (B & Surface Area) & Median $=1.57 \mathrm{~m}^{2}$ & \\
\hline
\end{tabular}

The most common histopathology was invasive ductal carcinoma (93\%; 343/368); 33\% (123/368) were at stage IIA, followed by stage IIIA (27\%) (Figures 1 and 2). 


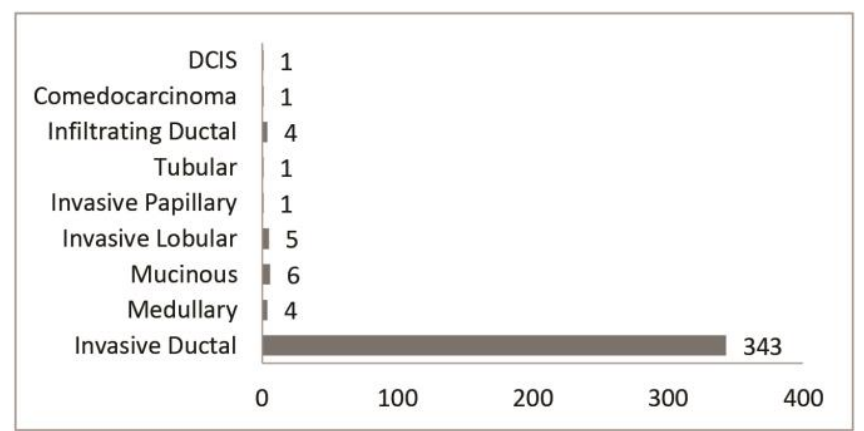

Figure 1. Histopathology, breast cancer patients, DOHBCMAP in PGH and JRRMMC

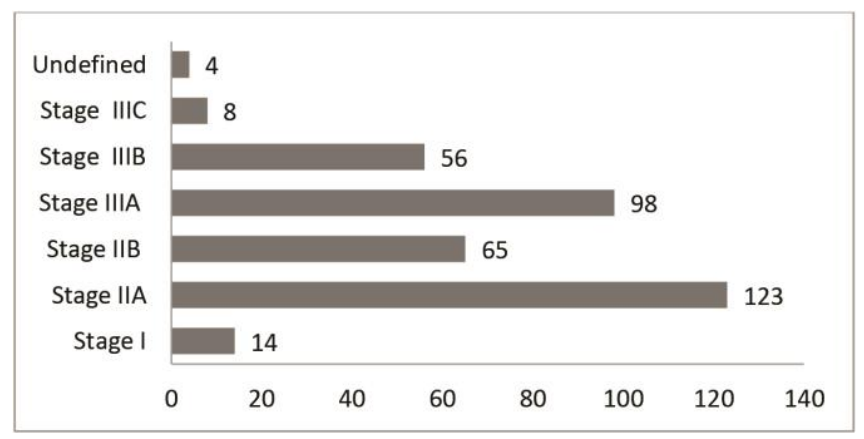

Figure 2. Stage of disease, breast cancer patients, DOHBCMAP in PGH and JRRMMC

By IHC results (Figure 3), HER2neu(-)/ER(-)/PR(-) disease was the most common IHC subtype at $20 \%$ $(\mathrm{n}=72 / 366)$ followed by the HER2neu(-)/ER(+)/PR(+) at $16 \%$ (57/366) and Her2neu(+)/ER(-)/PR(-) at 12\% (45/366).

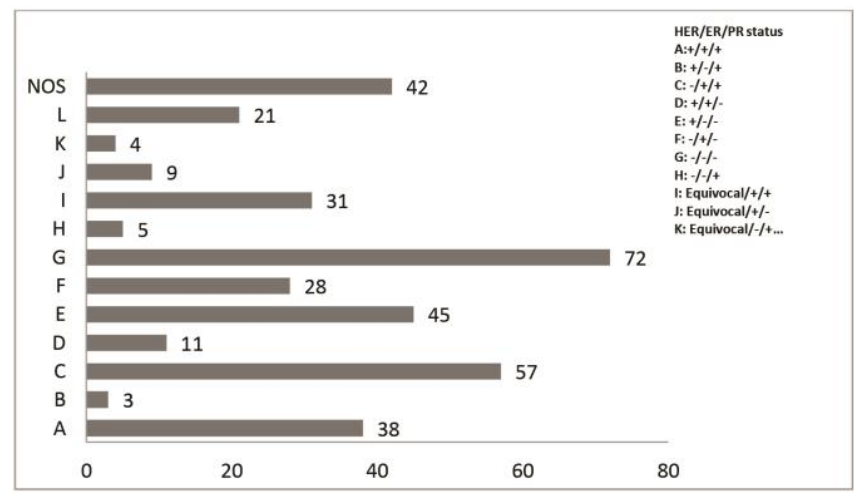

Figure 3. IHC subtypes, breast cancer patients, DOHBCMAP in PGH and JRRMMC

Among the three most common IHC subtypes (Figures 4 to 6), HER2neu(-)/ER(-)/PR(-) was noted to be common among ages 35-50 years old, in postmenopausal patients, and mostly in stage IIIA; HER2neu(-)/ER(+)/PR(+) was seen mostly among $>35$ years old, in peri-menopausal period, and in stage IIA; and HER2neu(+)/ER(-)/PR(-) subtype was seen in $>50$ years old, among postmenopausal, and in stage IIA.

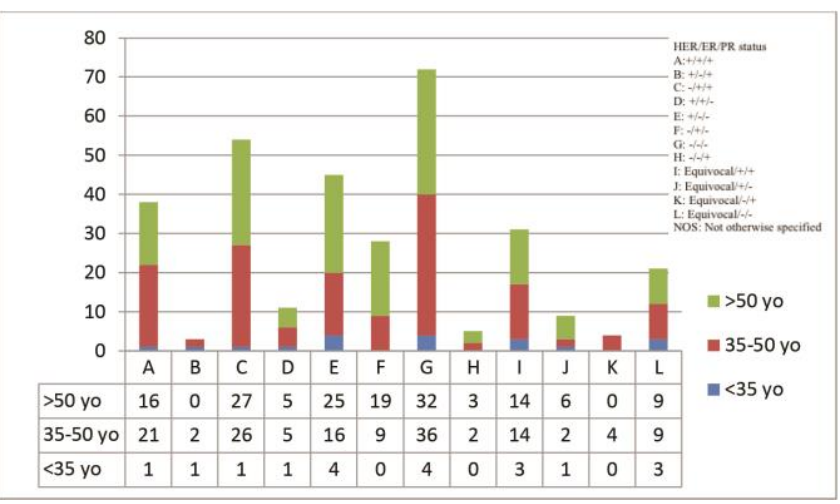

Figure 4. IHC subtypes by age group, breast cancer patients, DOH-BCMAP in PGH and JRRMMC

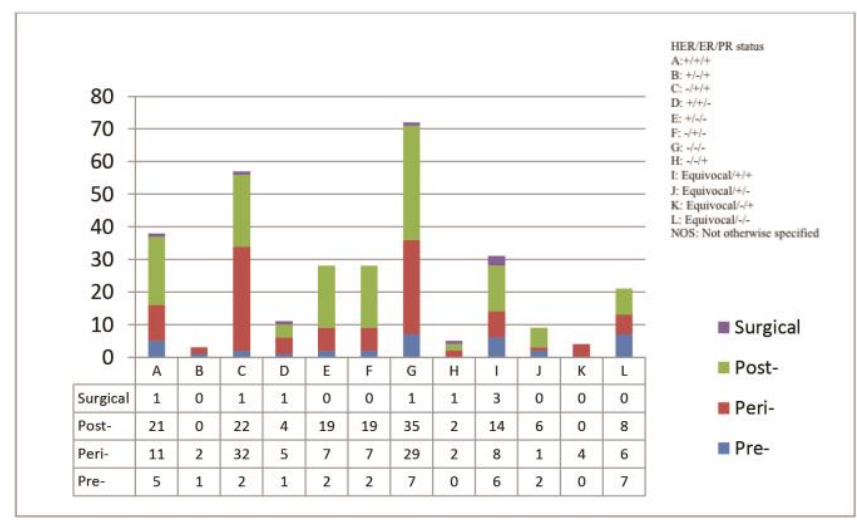

Figure 5. IHC subtypes by menopausal status, breast cancer patients, DOH-BCMAP in PGH and JRRMMC

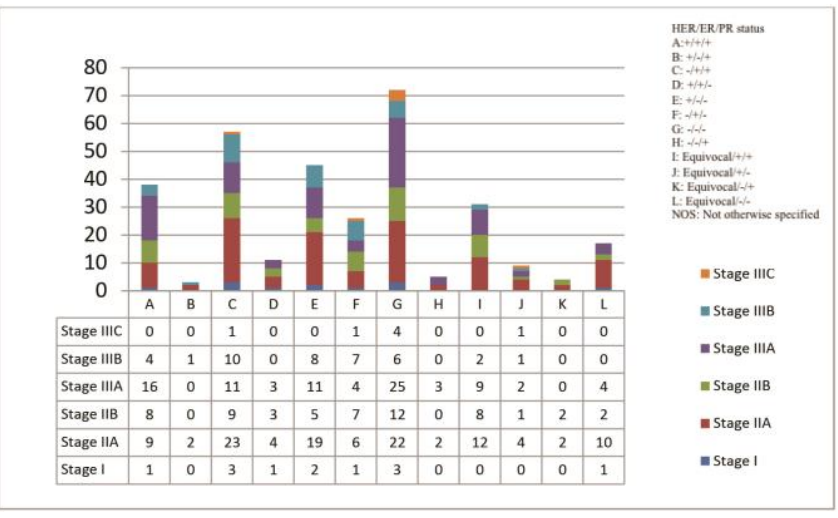

Figure 6. IHC subtypes by stage, breast cancer patients, DOH-BCMAP in PGH and JRRMMC

Modified radical mastectomy (MRM) was done in $87 \%$ and $10 \%$ had a biopsy-only procedure (these patients were Stage IIIB patients managed with neo-adjuvant chemotherapy prior to the planned definitive surgery) 
(Tables 3 and 4). Majority completed the prescribed chemotherapy $(87.77 \%)$, mainly adjuvant. The most common chemotherapy regimen was AC-T (adriamycin and cyclophosphamide, followed by docetaxel) in 59\% of cases. Five patients who were given tamoxifen alone had stage I, ER-positive disease.

Table 3. Treatment profile, breast cancer patients, DOHBCMAP in PGH and JRRMMC

\begin{tabular}{|c|c|c|c|}
\hline \multirow{2}{*}{\multicolumn{2}{|c|}{ Treatment Category }} & \multicolumn{2}{|c|}{ Total $(\mathrm{N}=368)$} \\
\hline & & Frequency & Relative Frequency (\%) \\
\hline \multicolumn{4}{|l|}{ Surgery } \\
\hline$\bullet$ & MRM & 323 & $87.77 \%$ \\
\hline$\bullet$ & Lumpectomy & 9 & $2.45 \%$ \\
\hline$\bullet$ & Biopsy & 36 & $9.78 \%$ \\
\hline \multicolumn{4}{|c|}{ Chemotherapy Regimen } \\
\hline • & CMF & 1 & $0.27 \%$ \\
\hline$\bullet$ & $\mathrm{AC}$ & 28 & 7.61 \\
\hline$\bullet$ & AC-T & 217 & $58.97 \%$ \\
\hline$\bullet$ & $\mathrm{TC}$ & 35 & 9.51 \\
\hline • & FAC & 82 & $22.28 \%$ \\
\hline$\bullet$ & Tamoxifen only & 5 & $1.36 \%$ \\
\hline \multicolumn{4}{|c|}{ Completion of Chemotherapy } \\
\hline$\bullet$ & Complete & 323 & $87.77 \%$ \\
\hline$\bullet$ & Incomplete & 45 & $13 \%$ \\
\hline \multicolumn{4}{|c|}{ Hormone therapy } \\
\hline$\bullet$ & Yes & 186 & $51.81 \%$ \\
\hline$\bullet$ & No & 173 & $48.19 \%$ \\
\hline \multicolumn{4}{|c|}{$\begin{array}{l}\text { Legend: MRM-Modified radical mastectomy; CMF-cyclophosphamide, methotrexate } \\
\text { 5-FU; AC-adriamycin, cyclophosphamide; AC-T-adriamycin, cyclophosphamide, ther } \\
\text { docetaxel; TC-docetaxel and cyclophosphamide; FAC-5-FU, adriamyxcin } \\
\text { cyclophosphamide. }\end{array}$} \\
\hline
\end{tabular}

Table 4. Chemotherapy regimen, by stage, breast cancer patients, DOH-BCMAP in PGH and JRRMMC

\begin{tabular}{|c|c|c|c|c|c|c|c|}
\hline \multirow{2}{*}{ Stage } & \multicolumn{6}{|c|}{ Chemotherapy Regimen } & \multirow{2}{*}{ Total } \\
\hline & CMF & AC & AC-T & TC & FAC & TAM & \\
\hline Stage & 0 & 0 & 7 & $1(7.14 \%)$ & 6 & 0 & 14 \\
\hline I & & & $(50 \%)$ & & $(42.86 \%)$ & & $(100 \%)$ \\
\hline Stage & 0 & 13 & 68 & 15 & 24 & 3 & 123 \\
\hline IIA & & $(10.57 \%)$ & $(55.28 \%)$ & $(12.20 \%)$ & $(19.51 \%)$ & $(2.44 \%)$ & $(100 \%)$ \\
\hline Stage & 0 & 4 & 51 & 3 & 6 & 1 & 65 \\
\hline IIB & & $(6.15 \%)$ & $(78.46 \%)$ & $(4.62 \%)$ & $(9.23 \%)$ & $(1.54 \%)$ & $(100 \%)$ \\
\hline Stage & 0 & 5 & 64 & 11 & 17 & 1 & 98 \\
\hline IIIA & & $(5.10 \%)$ & $(65.31 \%)$ & $(11.22 \%)$ & $(17.35 \%)$ & $(1.02 \%)$ & $(100 \%)$ \\
\hline Stage & 1 & 5 & 19 & 4 & 27 & 0 & 56 \\
\hline IIIB & $(1.79 \%)$ & $(8.93 \%)$ & $(33.93 \%)$ & $(11.43 \%)$ & $(48.21 \%)$ & & $(100 \%)$ \\
\hline $\begin{array}{l}\text { Legend: } \\
\text { cyclopho }\end{array}$ & $C M F-c$ & yclophospha & mide, $\quad m$ & ycthotrexat & $5-F U$ & $\begin{array}{l}\text { AC-adr } \\
\text { docetax }\end{array}$ & riamycin, \\
\hline
\end{tabular}

There was a total of $67(18 \%)$ patients with disease progression. Progression to distant sites was most common at $54 \%$, followed by local recurrences at $36 \%$. Site of disease progression was not specified in $10 \%$.

As seen in Table 5, Figures 7 and 8, HER2neu(-)/ ER(-)/PR(-) disease had the most disease progression or relapse at $24 \%$, followed by HER2neu(+)/ER(-)/PR(-) at $22 \%$, and then HER2neu(-)/ER(+)/PR(+) at $13 \%$. Relapse noted among HER2neu(-)/ER(-)/PR(-) subtype were mostly at distant sites, with metastases to the liver as the most common; likewise, HER2neu(+)/ER(-)/PR(-) had mainly distant metastatic locations with lung as the most common; HER2neu(-)/ER(+)/PR(+) subtype had mainly local recurrence, and if with distant relapse frequently this was noted in the bone.

Other HER2neu (+) subtypes such as subtypes A and D demonstrated disease progression more on the distant sites in lung and liver, respectively. Subtype-L [equivocal HER2neu/ER(-)/PR(-), which can be HER2neu(+) or HER2neu(-) group] had $8.95 \%$ disease progression mainly in distant sites.

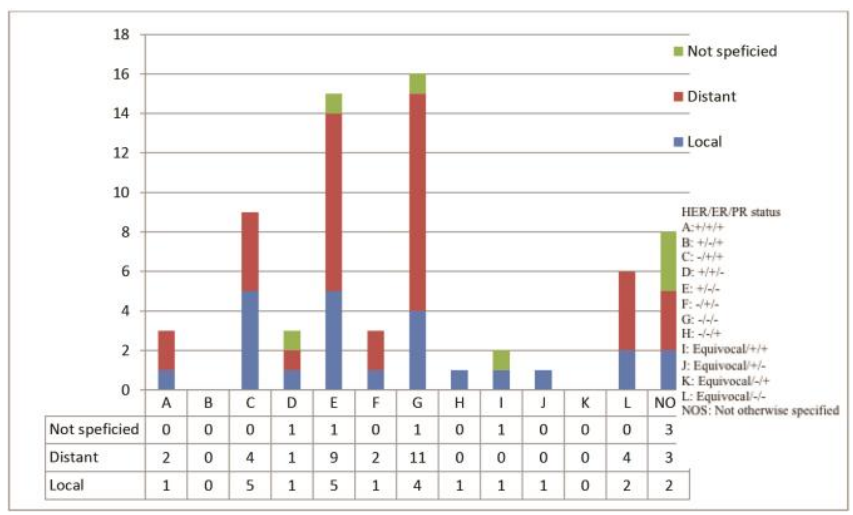

Figure 7. Disease progression site by IHC subtypes, breast cancer patients, DOH-BCMAP in PGH and JRRMMC

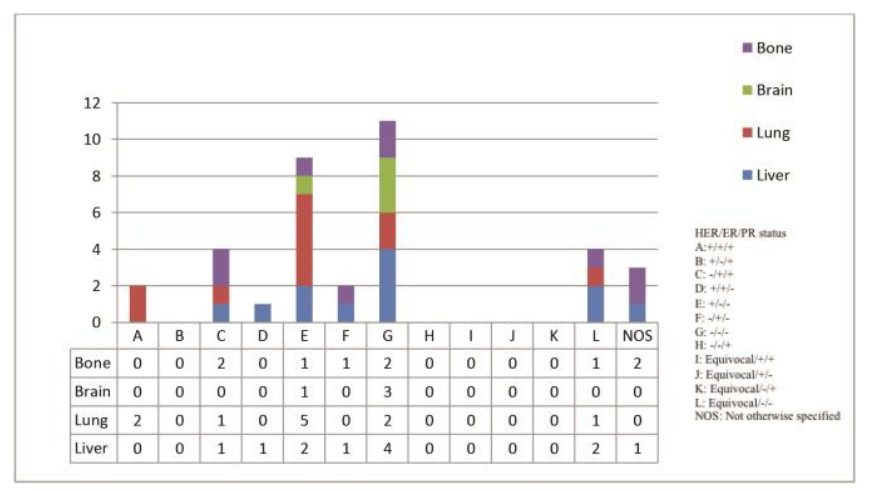

Figure 8. Distant metastatic sites by IHC subtypes of breast cancer patients, DOH-BCMAP in PGH and JRRMMC

TTP by IHC subtypes is shown in Table 6 . HER2neu(-)/ER(-)/PR(-) had the shortest median TTP at 11 months \pm 9 sd; HER2neu(+)/ER(-)/PR(-) showed a median TTP of 14 months \pm 8 sd; while HER2neu(-)/ER(+)/PR(+) had median TTP at 11.6 months $\pm 7.41 \mathrm{sd}$. Within the first $1-2$ years follow-up, however, the differences in the median TTP across all IHC subtypes were statistically comparable. 
Table 5. Disease progression by IHC subtypes, breast cancer patients, DOH-BCMAP in PGH and JRRMMC

\begin{tabular}{|c|c|c|c|c|c|}
\hline \multirow{2}{*}{$\begin{array}{c}\text { Subtypes: } \\
\text { Her2/ER/PR }\end{array}$} & \multicolumn{3}{|c|}{ Type and Site of Recurrences } & \multirow{2}{*}{$\begin{array}{c}\text { Total } \\
\text { Frequency }\end{array}$} & \multirow[t]{2}{*}{ Percentage } \\
\hline & Local & $\begin{array}{c}\text { Distant } \\
\text { Recurrence }\end{array}$ & $\begin{array}{c}\text { Not } \\
\text { specified }\end{array}$ & & \\
\hline $\mathrm{A}:+/+/+$ & 1 & 2 & - & 3 & $4.52 \%$ \\
\hline $\mathrm{B}:+/-/+$ & 0 & 0 & - & 0 & 0 \\
\hline$C:-/+/+$ & 5 & 4 & - & 9 & $13.43 \%$ \\
\hline $\mathrm{D}:+/+/-$ & 1 & 1 & 1 & 3 & $4.47 \%$ \\
\hline $\mathrm{E}:+/-/-$ & 5 & 9 & 1 & 15 & $22.38 \%$ \\
\hline F: $-/+/-$ & 1 & 2 & - & 3 & $4.47 \%$ \\
\hline G: -/-/- & 4 & 11 & 1 & 16 & $23.88 \%$ \\
\hline $\mathrm{H}:-/-/+$ & 1 & 0 & - & 1 & $1.49 \%$ \\
\hline I: $\mathrm{E} /+/+$ & 1 & 0 & 1 & 2 & $2.98 \%$ \\
\hline $\mathrm{J}: \mathrm{E} /+/-$ & 1 & 0 & - & 1 & $1.49 \%$ \\
\hline $\mathrm{K}: \mathrm{E} /-/+$ & 0 & 0 & - & 0 & 0 \\
\hline L: E/-/- & 2 & 4 & - & 6 & $8.95 \%$ \\
\hline NOS & 2 & 3 & 3 & 8 & $11.94 \%$ \\
\hline Total & 24 & 36 & 7 & $\mathrm{~N}=67$ & $100 \%$ \\
\hline
\end{tabular}

Table 6. TTP within 1-2 years follow-up by IHC subtypes, breast cancer patients, DOH-BCMAP in PGH and JRRMMC

\begin{tabular}{|c|c|c|c|c|}
\hline \multirow{2}{*}{$\begin{array}{c}\text { Subtypes } \\
\text { (Her- } \\
\text { 2/ER/PR); } \\
\text { (number who } \\
\text { went into } \\
\text { relapse) }\end{array}$} & \multicolumn{2}{|c|}{ TTP (DAYS/MONTHS) } & \multirow{2}{*}{$\begin{array}{l}\text { Cox Hazard } \\
\text { Ratio } \\
\text { (Exponential } \\
\text { coefficient) }\end{array}$} & \multirow{2}{*}{$\begin{array}{c}\mathrm{p}- \\
\text { value }\end{array}$} \\
\hline & $\begin{array}{c}\text { Median, }+ \text { SD } \\
\text { (days/months) }\end{array}$ & $\begin{array}{l}\text { Minimum and } \\
\text { Maximum days } \\
\text { (days/months) }\end{array}$ & & \\
\hline $\mathrm{A}:+/+/+;(\mathrm{n}=3)$ & $\begin{array}{l}260 \text { days } \pm 188 \text { days } \\
(8.2 \mathrm{mos} \pm 6.26 \text { mos })\end{array}$ & $\begin{array}{l}43 \text { to } 583 \text { days } \\
\text { (1.38 mos to } \\
19.43 \text { mos })\end{array}$ & 0.935 & 0.870 \\
\hline $\mathrm{B}:+/-/+$ & 0 & 0 & 1.457 & 0.717 \\
\hline$C:-/+/+;(n=9)$ & $\begin{array}{c}348 \text { days } \pm 222.39 \\
\text { days } \\
(11.6 \text { mos } \pm 7.41 \mathrm{mos})\end{array}$ & $\begin{array}{c}55 \text { to } 787 \\
\text { (1.83 mos to } 26.2 \\
\text { mos })\end{array}$ & 0.722 & 0.502 \\
\hline $\mathrm{D}:+/+/-;(\mathrm{n}=3)$ & $\begin{array}{c}497 \text { days } \pm 245.65 \\
\text { days } \\
(17 \text { mos } \pm 8.18 \mathrm{mos})\end{array}$ & $\begin{array}{c}\text { (1.4 mos to } 20.4 \\
\text { mos })\end{array}$ & 0.294 & 0.237 \\
\hline $\mathrm{E}:+/-/-;(\mathrm{n}=15)$ & $\begin{array}{c}415 \text { days } \pm 226.79 \\
\text { days } \\
(14 \text { mos } \pm 8 \text { mos })\end{array}$ & $\begin{array}{c}4 \text { to } 867 \\
(0.13 \text { mo to } 29 \\
\text { mos })\end{array}$ & 0.379 & 0.211 \\
\hline $\mathrm{F}:-/+/-;(\mathrm{n}=3)$ & $\begin{array}{c}493 \text { days } \pm 89.98 \\
\text { days } \\
(16 \text { mos } \pm 3 \text { mos })\end{array}$ & $\begin{array}{c}351-568 \\
(11.7 \text { mos-19 } \\
\text { mos })\end{array}$ & 0.794 & 0.575 \\
\hline G: $-/-/-;(n=16)$ & $\begin{array}{c}325.5 \text { days } \pm 253.9 \\
\text { days } \\
\text { (11 months } \pm 9 \\
\text { months })\end{array}$ & $\begin{array}{c}\text { 114- } 863 \text { days } \\
(3.8 \text { mosto } \\
29 \mathrm{mos})\end{array}$ & 0.000 & 0.975 \\
\hline $\mathrm{H}:-/-/+;(\mathrm{n}=1)$ & 163 (6 months) & - & 0.570 & 0.208 \\
\hline I: $E /+/+;(n=2)$ & $\begin{array}{c}340 \text { days } \pm 250.14 \\
\text { days } \\
(11 \text { mos }+8 \text { mos })\end{array}$ & $\begin{array}{l}104-793 \text { days } \\
(3.46 \text { mos to } \\
26.43 \text { mos })\end{array}$ & 1.142 & 0.834 \\
\hline $\mathrm{J}: \mathrm{E} /+/-;(\mathrm{n}=1)$ & 205 days (6.83 mos) & - & 0.725 & 0.405 \\
\hline $\mathrm{K}: \mathrm{E} /-/+$ & 0 & 0 & 0.580 & 0.263 \\
\hline $\mathrm{L}: \mathrm{E} /-/-; \quad(\mathrm{n}=6)$ & $\begin{array}{c}123.5 \text { days } \pm 277.01 \\
\text { days } \\
(4 \operatorname{mos} \pm 9 \mathrm{mos})\end{array}$ & $\begin{array}{c}\text { 51-811 days } \\
(1.7 \text { mos to } 27 \\
\text { mos })\end{array}$ & 0.638 & 0.188 \\
\hline
\end{tabular}

Legend: (+) positive; (-) negative; (E) equivocal

Over the first 1-2 years follow-up, across all IHC subtypes (Table 7, Figures 9 and 10), the DFS and OS rates were comparable. The overall DFS was at $69 \%$ and overall OS rate at $74 \%$ (Table 7 ).
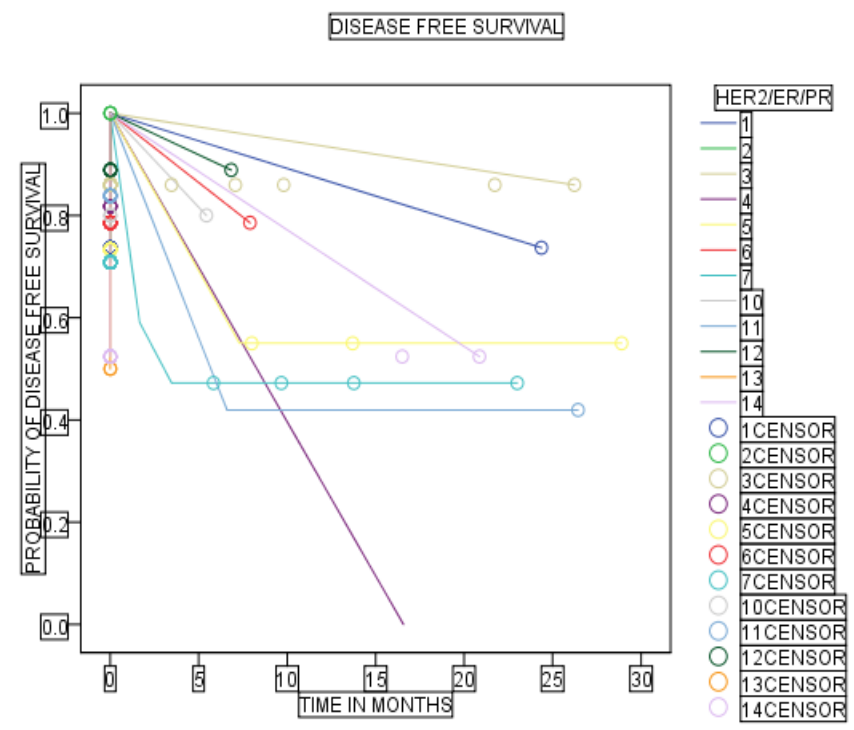

\begin{tabular}{|l|c|c|c|}
\hline \multicolumn{1}{|c|}{ Parameter } & Chi-Square & df & Sig. \\
\hline Log Rank (Mantel-Cox) & 14.485 & 11 & 0.207 \\
\hline Breslow (Generalized Wilcoxon) & 15.456 & 11 & 0.163 \\
\hline Tarone-Ware & 15.407 & 11 & 0.165 \\
\hline
\end{tabular}

Figure 9. 1-2 years DFS Kaplan Meier Curve by IHC subtypes, breast cancer patients, DOH-BCMAP in PGH and JRRMMC

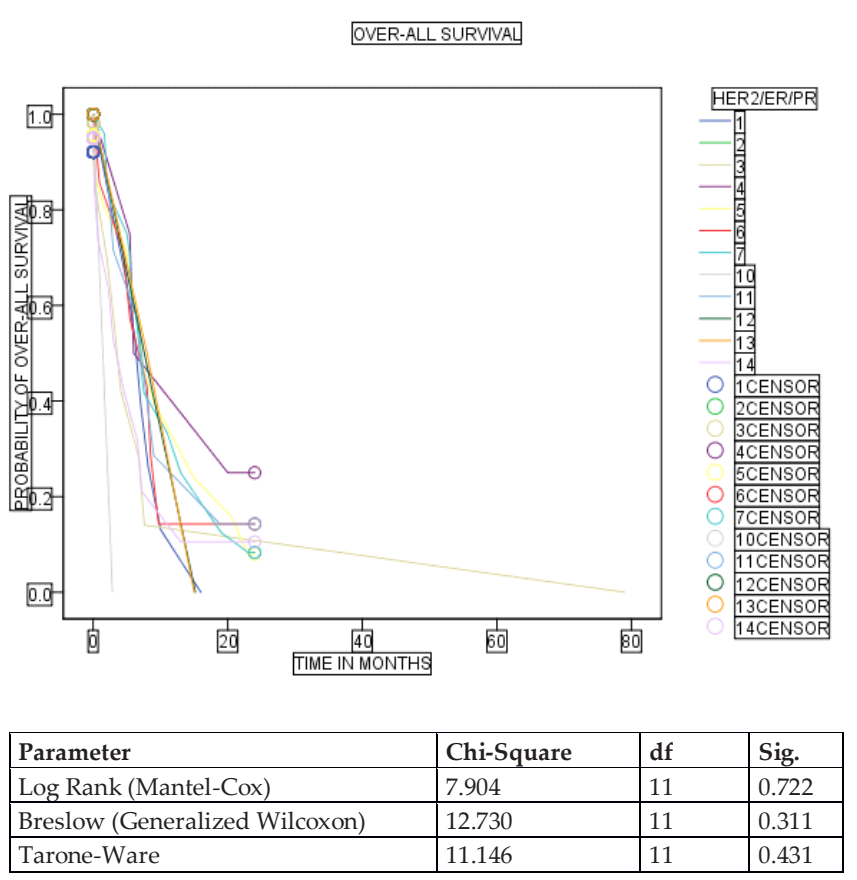

Figure 10. 1-2 years OS Kaplan Meier Curve by IHC subtypes, breast cancer patients, DOH-BCMAP in PGH and JRRMMC 
Table 7. DFS and OS rates over $1^{\text {st }} 2$-years of Follow-up by IHC subtypes, breast cancer patients, DOH-BCMAP, PGH and JRRMMC

\begin{tabular}{|c|c|c|c|c|c|c|c|c|}
\hline IHC Subtypes & $\begin{array}{l}\text { Total patients enrolled } \\
\text { (N) }\end{array}$ & PD & NED & Dead & LTF & Alive & $\begin{array}{l}\text { DFS rate at } 1-2 \text { years } \\
\left(\mathrm{NED} / \mathrm{N}^{*} 100\right)\end{array}$ & $\begin{array}{l}\text { OS rate at } 1-2 \text { years } \\
\left.\text { (Alive/ } \mathrm{N}^{*} 100\right)\end{array}$ \\
\hline $\mathrm{A}:+/+/+$ & 38 & 3 & 28 & 5 & 5 & 28 & $73.68 \%$ & $73.68 \%$ \\
\hline B: $+/-/+$ & 2 & 0 & 2 & 0 & 0 & 2 & $100 \%$ & $100 \%$ \\
\hline C: $-/+/+$ & 57 & 9 & 48 & 1 & 7 & 49 & $84.21 \%$ & $85.96 \%$ \\
\hline $\mathrm{D}:+/+/-$ & 11 & 3 & 8 & 2 & 1 & 8 & $72.72 \%$ & $72.72 \%$ \\
\hline $\mathrm{E}:+/-/-$ & 45 & 15 & 30 & 8 & 5 & 32 & $66.67 \%$ & $71.71 \%$ \\
\hline F: $-/+/-$ & 28 & 3 & 19 & 0 & 6 & 22 & $67.85 \%$ & $78.57 \%$ \\
\hline G: $-/-/-$ & 72 & 16 & 41 & 8 & 15 & 49 & $56.94 \%$ & $68.05 \%$ \\
\hline $\mathrm{H}:-/-/+$ & 5 & 1 & 4 & 0 & 1 & 4 & $80 \%$ & $80 \%$ \\
\hline I: $E /+/+$ & 31 & 2 & 24 & 1 & 5 & 25 & $77.42 \%$ & $80.64 \%$ \\
\hline $\mathrm{J}: \mathrm{E} /+/-$ & 9 & 1 & 7 & 0 & 1 & 8 & $77.78 \%$ & $88.88 \%$ \\
\hline $\mathrm{K}: \mathrm{E} /-/+$ & 4 & 0 & 2 & 2 & 0 & 2 & $50 \%$ & $50 \%$ \\
\hline L: E/-/- & 21 & 6 & 9 & 4 & 6 & 11 & $42.85 \%$ & $52.38 \%$ \\
\hline Total & 323 & 59 & 222 & 31 & 52 & 240 & $\begin{array}{l}\text { Overall DFS } \\
\text { rate: } 68.73 \%\end{array}$ & $\begin{array}{c}\text { Overall OS rate: } \\
74.30 \%\end{array}$ \\
\hline
\end{tabular}

Legend: (+) positive; (-) negative; (E) equivocal; $P D$, progressive disease; NED, no evidence of disease;

LTF, lost to follow-up; DFS, disease free survival; OS, overall survival. Subtype not otherwise specified were

\section{Discussion}

Breast cancer is known to be a heterogeneous disease and the biology has been defined into groups of unique biological subtypes. Gene expression studies using DNA microarray and IHC staining have identified these several distinct breast cancer subtypes with each subtype presenting a particular clinical, pathological and molecular phenotype associated with diverse natural histories, therapeutic implications and prognoses. Molecular and/or IHC sub-typing has been considered as standard of care for breast cancer management, which classify breast cancer into six different subtypes according to the Her2-neu, ER, PR, and CK5/6 EGFR expression status. ${ }^{3}$ Luminal-A $[$ HER2neu(-)/ER(+)/PR(+)/CK5/6 EGFR(-)] is the most predominant subtype and has the better prognosis among subtypes. ${ }^{4}$ Luminal B [(ER(+/-) PR(+/-) HER2neu(-/+) CK5/6 EGFR(-)] has a more aggressive phenotype, higher histological grade and proliferative index, and worse prognosis compared to luminal A. ${ }^{3}$ Her2-enriched [ER(-)/PR(-)/HER2neu(+)/CK5/6 EGFR(+/-)] and triplenegative or basal-like [ER(-)/PR(-)/HER2neu(-)/CK5/6 EGFR(+)] and claudin-low [ER(-)/PR(-)/HER2neu(-)/CK5/6 EGFR (+/-)] are considered to have a poor prognosis with the latter having a higher relapse rate in the first 3 years ${ }^{5}$, and an aggressive pattern of metastatic relapse with preponderance for visceral organs, mainly lung, central nervous system and lymph nodes. ${ }^{7}$

In this study, the ER(-)/PR(-)/HER2neu(-) (subtype-G) was the most frequent subtype. This is similar in some ethnic groups. ${ }^{2}$ A study done among Asian patients treated in two New York City institutions in 2012 found that Chinese and Japanese had a higher proportion of good-prognosis luminal-A cancers compared to Filipinos and Koreans ( $\mathrm{p}=$ 0.001); Koreans had a higher proportion of triple negative cancers compared to other ethnic groups $(p=0.06) ;{ }^{20}$ Filipinos were noted to have a higher proportion of
HER2neu positive cancers (45.6\%) compared to other ethnic groups $(p=0.002) .{ }^{20}$ In this study, if we were to take all HER2neu positive patients, this proportion would be $31 \%$ (with exclusion of equivocal results).

In one study, ${ }^{22}$ the basal cell-like subtype (triple negative) was noted to be the most prevalent in the age group of $<35$ years old and showed an age-specific bimodal distribution with a peak at: (a) <35 years old; and (b) 51 to 65 years of age; the molecular subtypes did not differ in terms of menopausal status. In this study, HER2neu(-)/ER(-)/PR(-) disease was mostly noted between the age group of 35-50 years old and mostly postmenopausal. HER2neu(-)/ $\mathrm{ER}(+) / \mathrm{PR}(+)$ and HER2neu(+) subtypes were more prevalent in $>35$ years old, peri-menopausal and >50 years old, postmenopausal, respectively.

Breast cancer among $<35$ years of age was also noted in this study at $7 \%$. According to a study ${ }^{23}$ among young girls in Turkey, young patients had high risk features such as the luminal B subtype, moderate to high grade tumors, stage II disease, and with positive axillary and lymphovascular invasion. Another study ${ }^{24}$ done in Korea showed unfavorable features of $<35$ years old patients, frequently associated with triple-negative subtypes and higher histologic and nuclear grade.

The stage of breast cancer at diagnosis also correlates with prognosis and IHC subtypes. In this study, HER2neu(-)/ER(-)/PR(-) disease was diagnosed mostly in stage IIIA disease; HER2neu(-)/ER(+)/PR(+) and HER2neu(+)/ER(-)/PR(-)tumors presented predominantly as stage IIA disease.

Since HER2neu(-)/ER(-)/PR(-) and Her2neu (+) subtypes are both considered as highly aggressive, highly proliferative, and with poor prognosis, these subtypes are expected to have the most number of early relapses, mostly at distant sites, as so commonly discussed in literature. The Her2-enriched subtype has changed in clinical outcome 
nowadays with the advent and administration of trastuzumab as targeted therapy against the Her2neu receptor, ${ }^{3,4,7}$ similar to the change in clinical outcome with the discovery of tamoxifen as a targeted therapy for ER(+) tumors. The triple negative subtype remains to have early recurrences higher in the first 3 years after diagnosis; a targeted agent against this subtype is yet to be discovered. ${ }^{25}$ Luminal-A subtypes mostly have a better prognosis with a relapse rate of $27.8 \%$ and survival from the time of relapse (median 2.2 years) significantly better than other subtypes with a distinct pattern of recurrence more of bone metastases $(18.7 \%){ }^{4}$

The DFS and OS of the patients enrolled in DOHBCMAP during the first 1-2 years of follow-up were comparable among the subtypes; the overall DFS and OS rates were $68.73 \%$ and $74.30 \%$, respectively. The HER2neu(-)/ER(-)/PR(-) subtype had the shortest median TTP (11 months \pm 9 sd) among those with high number of relapse together with $\operatorname{Her} 2(+) / \operatorname{ER}(-) / P R(-)$ and HER2neu(-)/ER(+)/PR(+) subtypes, with median TTP of 14 months $\pm 8 \mathrm{sd}$, and 11.6 months $\pm 7.41 \mathrm{sd}$, respectively.

If subtypes were to be combined, disease progression/relapse during the first 1-2 years of follow-up would be seen mostly among the HER2neu(+) subtypes regardless of ER/PR status at $32 \%$, compared to HER2neu(-)/ER(-)/PR(+/-) at 25\%. Both groups would have predominantly distant metastasis during relapse. This was $18 \%$ among the HER2neu(-)/ER(+)/PR(+/-) group, which had predominantly local recurrence.

The TTP, DFS, and OS may change as the patients are followed-up over 5 years, particular without trastuzumab treatment for HER2neu(+) patients. The 65 (18\%) patients with equivocal HER2neu status, particularly those with ER(-) disease (25 patients), could contribute to unfavorable TTP and poor prognosis among these patients if HER2neu was positive.

The determination of gene amplification among the equivocal HER2neu patients plus the CK5/6 EGFR status (molecular profile) of all patients would perhaps add more information to the prognostication of this disease, but the specific HER2neu/ER/PR IHC profiles can define breast cancer prognosis and predict treatment outcomes given HER2neu(+), HER2neu(-)/ER(-), and HER2neu(-)/ER(+) disease.

\section{Conclusion}

Filipino patients enrolled in the DOH-BCMAP with non-metastatic breast cancer after surgery and mainly on adjuvant chemotherapy started to develop disease progression/ relapse within the first 2 years of follow-up; $82 \%$ had no relapse. At these early years of follow-up, the median TTPs, DFS rate, OS rate among the different breast cancer IHC subtypes were comparable, although HER2neu(+) regardless of ER/PR subtype trended to have more disease progression, followed by HER2neu(-)/ ER(-)/ regardless of PR subtype, and then HER2neu(-)/ ER(+)/ regardless of PR subtype. IHC resultant HER2neu(+) regardless of ER/PR and HER2neu(-)/ER(-)/PR(-/+) subtypes can serve as early prognosticators of breast cancer relapse.

\section{References}

1. The global burden of disease: WHO Library Cataloguing-in-Publication Data. 2004 update.

2. Laudico AV, Medina VBS, et al. 2010 Philippine Cancer Facts and Estimates. Manila:Philippine Cancer Society, Inc.; 2010.

3. Eroles P, Bosch A, Pérez-Fidalgo JA, LluchA. Molecular biology in breast cancer: intrinsic subtypes and signaling pathways. Cancer Treat Rev. 2012; 38(6):698-707.

4. Kennecke H, Yerushalmi R, Woods R, et al. Metastatic behavior of breast cancer subtypes. J ClinOncol. 2010; 28(20):3271-7.

5. Dent R, Trudeau M, Pritchard KI, et al. Triple-negative breast cancer: clinical features and patterns of recurrence. Clin Cancer Res. 2007; 13(15Pt 1): 4429-34

6. Livasy CA, Karaca G, Nanda R, et al. Phenotypic evaluation of the basal-like subtype of invasive breast carcinoma. Mod Pathol. 2006; 19(2):264-71.

7. Smid M, Wang Y, Zhang Y, et al. Subtypes of breast cancer show preferential site of relapse. Cancer Res. 2008; 68(9):3108-14.

8. Staaf J, Ringner M, Vallon-Christersson J, et al. Identification of subtypes in human epidermal growth factor receptor 2 - positive breast cancer reveals a gene signature prognostic of outcome. J ClinOncol. 2010; 28(11):1813-20.

9. Perou CM, Sorlie T, Eisen MB, et al. Molecular portraits of human breast tumours. Nature. 2000; 406(6797):747-52.

10. Weigelt B, Mackay A, A'Hern R, et al. Breast cancer molecular profiling with single sample predictors: a retrospective analysis. Lancet Oncol. 2010; 11(4): 339-49.

11. Rouzier R, Perou CM, SymmansWF, et al. Breast cancer molecular subtypes respond differently to preoperative chemotherapy. Clin Cancer Res. 2005; 11(16):5678-85

12. Engstrøm MJ, Opdahl S, Hagen AI, et al. Molecular subtypes, histopathological grade and survival in a historic cohort of breast cancer patients. Breast Cancer Res Treat. 2013; 140(3):463-73.

13. Dent R, Trudeau M, Pritchard KI, et al. Triple-negative breast cancer: clinical features and patterns of recurrence. Clin Cancer Res. 2007; 13(15 Pt 1):4429-34.

14. Carey LA, Perou CM, Livasy CA, et al. Race, breast cancer subtypes, and survival in the Carolina Breast Cancer Study. JAMA. 2006; 295(21):2492-502.

15. Schnitt SJ.Classification and prognosis of invasive breast cancer: from morphology to molecular taxonomy. Mod Pathol. 2010; 23Suppl 2:S60-4.

16. Shawarby MA, AlTamimi DM, Ahmed A. Molecular classification of breast cancer: an overview with emphasis on ethnic variations and future perspectives. Saudi Journal of Medicine and Medical Sciences. 2013; 1(1):14-19.

17. Onitilo AA, Engel JM, Greenlee RT, Mukesh BN. Breast Cancer Subtypes Based on ER/PR and Her2 Expression: comparison of clinicopathologic features and survival. Clin Med Res. 2009; 7(1-2):4-13.

18. Yang XR, Sherman ME, Rimm DL, et al. Differences in risk factors for breast cancer molecular subtypes in a population-based study. Cancer Epidemiol Biomarkers Prev. 2007;16(3):439-43.

19. Kwan ML, Kushi LH, Weltzien E, et al. Epidemiology of breast cancer subtypes in two prospective cohort studies of breast cancer survivors. Breast Cancer Res. 2009; 11(3):R31.

20. Chuang E, Paul C, Flam A, et al. Breast cancer subtypes in Asian-Americans differ according to Asian ethnic group. J Immigr Minor Health. 2012; 14(5):754-8.

21. Kakarala M, Rozek L, Cote M, Liyanage S, Brenner DE. Breast cancer histology and receptor status characterization in Asian Indian and Pakistan women in the U.S. - a SEER analysis. BMC Cancer. 2010; 10:191.

22. Themelandu CU, LeffallLDJr, Dewitty RL, et al. Molecular breast cancer subtypes in premenopausal and postmenopausal African-American women: age-specific prevalence and survival. J Surg Res. 2007; 143(1):109-18.

23. Goksu SS, Tastekin D, Arslan D, et al. Clinicopathologic features and molecular subtypes of breast cancer in young women (age $\leq 35$ ). Asian Pac J Cancer Prev. 2014; 15(16):6665-8

24. Kim JY, Chang SK, Park H, Lee BM, Shin HS. Treatment outcome in patients with triple negative early stage breast cancers compared with other molecular subtypes. Radiat Oncol J. 2012; 30(3):124-31.

25. Suresh P, Batra U, Doval DC. Epidemiological and clinical profile of triple negative breast cancer at a cancer hospital in North India. Indian J Med Paediatr Oncol.2013; 34(2):89-95. 